should wish to do so. The problems now posed by motor-cars and drugs are in many ways similar. We must ensure that the price of advance is not too high and that accidents are reduced to a minimum by foresight and care. Both are examined, licensed, and periodically reviewed. Roads and lines of communication of information are improved. The manufacturers are exhorted to introduce the latest safety devices and tests. However, in the final analysis, most depends on the driver and prescriber.

\section{REFERENCES}

Barr, D. P. (1955). 7. Amer. med. Ass., 159, 1452

Brit. med. F., 1964, 1, 578

Cahal, D. A.' (1965). Lancet, 2, 441.

Eisen, M. J. (1964). 7. Amer. med. Ass., 189, 64.

Evans, D. A. P. (1963). Amer. F. Med., 34, 639.

- Manley, K. A., and McKusick, V. A. (1960). Brit. med. 7., 2, 485

Evans, F. T., Gray, P. W. S., Lehmann, H., and Silk, E. (1953). 'Ibid., $1,136$.

Gírdwood, R. H. (1952). Ibid., 1, 599.

Fogg, J. (1965). Lancet, 2, 31 .
Hodgman, J. E. (1961). Pediat. Clin. N. Amer., 8, 1027.

Hunter. R., Earl, C. J., and Thornicroft, S. (1964). Proc. roy. Soc. Med., 51,758 .

Kalow, W. (1952). Pharmacogeneitcs, Herecii.y, and the Response to Drugs. Saunders, Philadelphia.

Kerr, D. N. S., and Davidson, S. (1958). Lancet, 2, $48 y$.

Kiloh, L. G., and Brandon, S. (1962). Brit. med. F., 2, 40.

Kilpatrick, R., and Whyie, J. H. S. (1965). Ibid., 1, 316.

Klerman, G. L., and Cole, J. O. (1965). Pharmacol. Rev., 17, 101

Kuenssberg, E.' V. (1965). Brit. med. f., 1, 983.

Lasagna, L. (1964). Perspect. Biol. Med., 7, 457. Lehmann, H., Liddell, J., Blackwell, B., O'Connor, D. C., and Daws,

MacDonald, M. G., and MacKay, B. R. (1964). F. Amer. med. Ass., 190, 1071

Medical Research Council (1950). Brit. med. f., 2, 425.

Meyler, L., and Peck, H. M. (1962). Drug-induced Diseases. Thomas,

Springfield, 111.
Moser, R. H. (1964). Diseases of Medical Progress, 2nd ed. Thomas, Springfield, 111 .

Ruddell, J. S. (1962). Lance:. 1, 832

Schimmel, E. M. (1963). f. chron. Dis., 16, 1

Spain, D. M. (1963). The Complications of Modern Medical Practices. Grune and Stratton, New York.

Speirs, A. L. (1962). Lancet, 1, 303.

Vere, D. W' (1965). Ibid., 1, 370.

Wilson, G. M. (1961). Ibid., 1, 1109.

\title{
Hyaline and Calcified Pleural Plaques as an Index of Exposure to Asbestos
}

\section{A Study of Radiological and Pathological Features of 100 Cases with a Consideration of Epidemiology}

\author{
D. O'B. HOURIHANE,* M.D., M.R.C.P.I., D.C.P. ; LEILA LESSOF, $†$ M.B., B.S., D.M.R.D. \\ P. C. RICHARDSON, $\ddagger$ M.B., B.S., B.SC., M.R.C.P.
}

Brit. med. F., 1966, 1, 1069-1074

Benign collagenous pleural thickening is a common finding at necropsy in cases of asbestosis (Gloyne, 1933), and calcification may occur within the thickened serosa (Gloyne, 1938). Focal pleural calcification may be noted radiologically in asbestosis (Hurwitz, 1961 ; Lawson, 1963), but may also be seen in those who work with asbestos or other silicates without evidence of pulmonary disease (Smith, 1952). There is strong evidence from Finland (Kiviluoto, 1960) that environmentalthat is, non-industrial-exposure to asbestos leads to the relatively common finding of focal pleural calcification (calcified pleural plaques) in a community.

This paper is concerned with the association between pleural plaques as seen at necropsy or in routine chest radiographs and exposure to asbestos, and we wish to emphasize the potential epidemiological value of radiology is assessing the prevalence of these lesions in a population.

There were 56 cases in which pleural plaques ere found at necropsy, and 50 cases in which pleural calcification was seen on $x$-ray examination. Six of the patients from the radiological series had the presence of plaques confirmed at necropsy, so that the total number of cases with pleural plaques is 100 .

\section{Pathology}

Hyaline pleural plaques occur as discrete elevated grey-white areas, usually involving the parietal layer and without associated effusion or adhesions (Fig. 1). The plaques vary greatly in size and shape, and the intervening pleura and unaffected visceral layer show a slight, diffuse thickening (Fig. 1). The cut surface is of a uniform glistening grey colour unless focal calcification is present, when yellow spots or laminae may also be seen. Focal calcification within plaques is shown in $x$-ray films of parietal pleura in Figs. 2 and 3. Plaques are usually bilateral, most prominent in the lower halves of the pleurae, and tend to follow the lines of the ribs (Figs. 1, 2, and 3). Although theic consistency is that of cartilage, histologically they are composed of laminated hyaline collagen and often show either spotty or massive focal calcification (Fig. 4). There is no suggestion of vascularity or of granulation tissue when examined post mortem, although surface fibrin incorporated into a plaque was observed in one case.

We could detect no other histological difference between plaques with some calcification and those with none, and we have used the term "hyaline pleural plaques" to refer to all of them.

\section{Necropsy Prevalence}

From 1 January to 31 December 1964 a personal examination of each necropsy at the Bernhard Baron Institute was attempted, and 16 cases with these plaques were found. There was no tuberculosis in the chest in any case, and after histological examination only two cases could be defined as " asbestosis" (pulmonary fibrosis due to asbestos). The total number of necropsies during 1964 was 381 .

\footnotetext{
* Lecturer in Pathology, London Hospital Medical School. Present address: School of Pathology, Trinity College, Dublin.

+ Late Senior Registrar in Ragi, Trinity College, Dublin.

₹ Senior Medical Registrar, Department of Medicine, London Hospital.

Reprints from Dr. D. O'B. Hourihane, School of Pathology, Trinity 
The incidence of these plaques is therefore at least $4.2 \%$ of all necropsies here. This is a minimal figure, as many necropsies were not in fact personally examined, and it is a simple matter to overlook these lesions in the post-mortem room unless care is taken to clean the pleura and examine all its surfaces. During 1965 a vigorous effort was made to attend all necropsies, including those performed by the Department of Forensic Medicine. The incidence during January-March was 15 of 134 necropsies $(11.2 \%)$. Several of the plaques had tumours at their edges, either metastatic or primary diffuse mesothelioma, so it seemed that these lesions often interrupted the otherwise continuous spread of tumour on the pleural membrane, or that the lymphatics in these areas were blocked, and, consequently, trapped neoplastic cells preferentially. The presence of aggregates of carbon at the edges of many plaques also suggests lymphatic obstruction.

In addition to these 31 cases detected during routine necropsies at the Bernhard Baron Institute of Pathology nine cases were received from other pathologists during 1964 ; and plaques were found post mortem in an additional 16 subjects with clinical asbestosis who had been cared for at the London Hospital.

\section{Association of Pleural Plaques with Asbestos}

A sensitive and quick method for detecting asbestos bodies was found to be histological examination of routinely processed

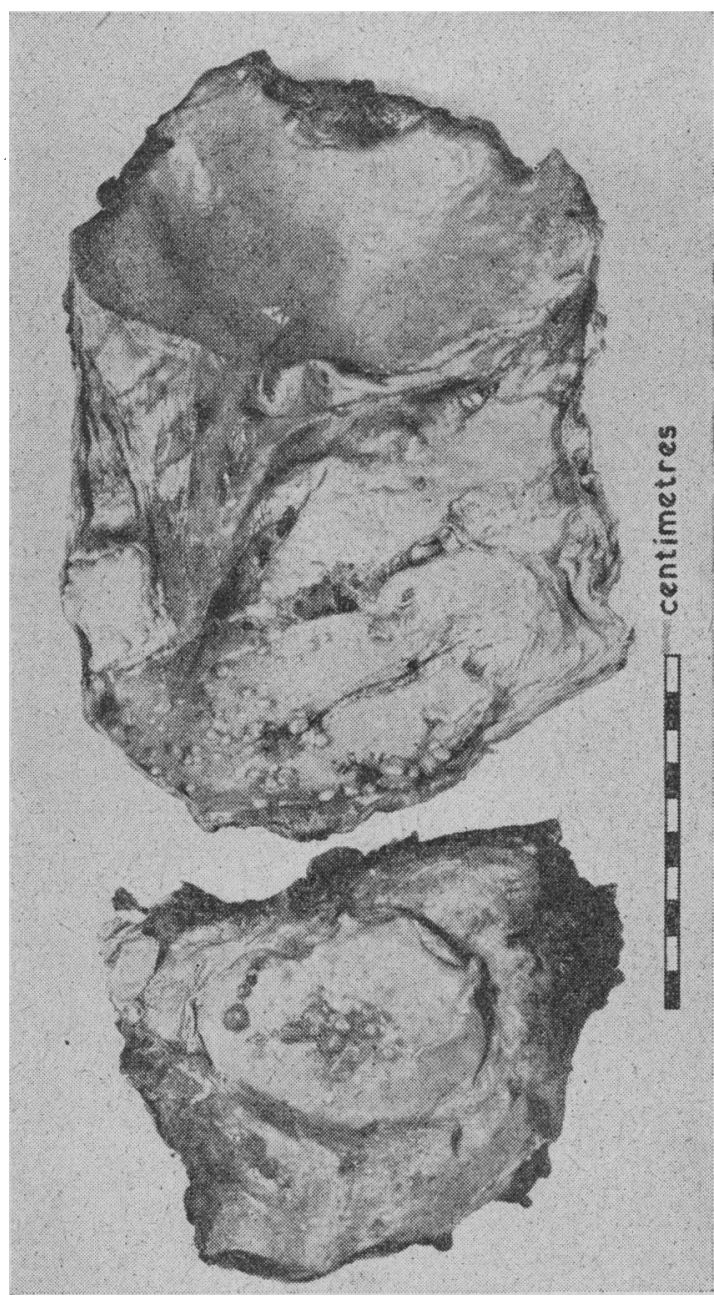

FIG. 1.-Left parietal pleura (upper) and left dome of diaphragm. The plaque in uppermost part is unusually large; the smooth oval plaques below it are of the type commonly seen. Noie the tendency to follow the direcion of the ribs, and the small nodular proections in the lower part of specimen and on the surface of the diaphraomatic plarues. No history of exposure to asbestos, but asbestos bodies in sputum and lung. Patient died with peritoneal mesothelioma. basal lung tissue, cut at $30 \mu$ and mounted unstained (Hourihane, $1965 \mathrm{a}$ ). With this technique the lungs from 115 routine necropsies were examined, and classical asbestos bodies were found in $28(24.3 \%)$. The number of blocks examined from positive and that from negative cases were comparable.

The lungs from each case in which pleural plaques were present were similarly examined, and, without exception, asbestos bodies were found in all 56. This was to be expected in the 16 cases of clinical asbestosis and the eight cases in which only histological evidence of asbestosis was found, consisting of pulmonary fibrosis associated with asbestos bodies and fibres. In the remaining 32 cases there had been no pulmonary reaction to the asbestos. The association between the plaques and asbestos bodies in the lungs is statistically significant $(P<0.01)$ when compared with the control series, whether the cases of asbestosis are included or not.

Attempts were made to identify asbestos within some of the plaques by means of a technique of incineration and phasecontrast microscopy. which had already proved successful in dealing with mesotheliomata (Hourihane, 1965b). Histological preparations from 12 cases were incinerated, and asbestos fibres were found in four of them.

The mode of origin of these lesions is uncertain ; they may be formed by the incorporation of fibrin into the pleura and its subsequent alteration to stain as collagen (Heard and Williams, 1961), or by the formation of collagen de novo. Either mechanism might be initiated by the presence of asbestos fibres in the pleural tissues; possibly the parietal pleura is predominantly affected, because the lymphatics here are subjected less to the milking movements of the chest viscera.

Tuberculosis has always been accepted as a cause of these plaques, and we have excluded any such from this study. We have in fact seen one case with a tuberculous lesion of the pleura in which there was a hyaline plaque of the parietal pleura of identical histology to those already described. No asbestos was found in the lungs of this case. No radiograph was available.

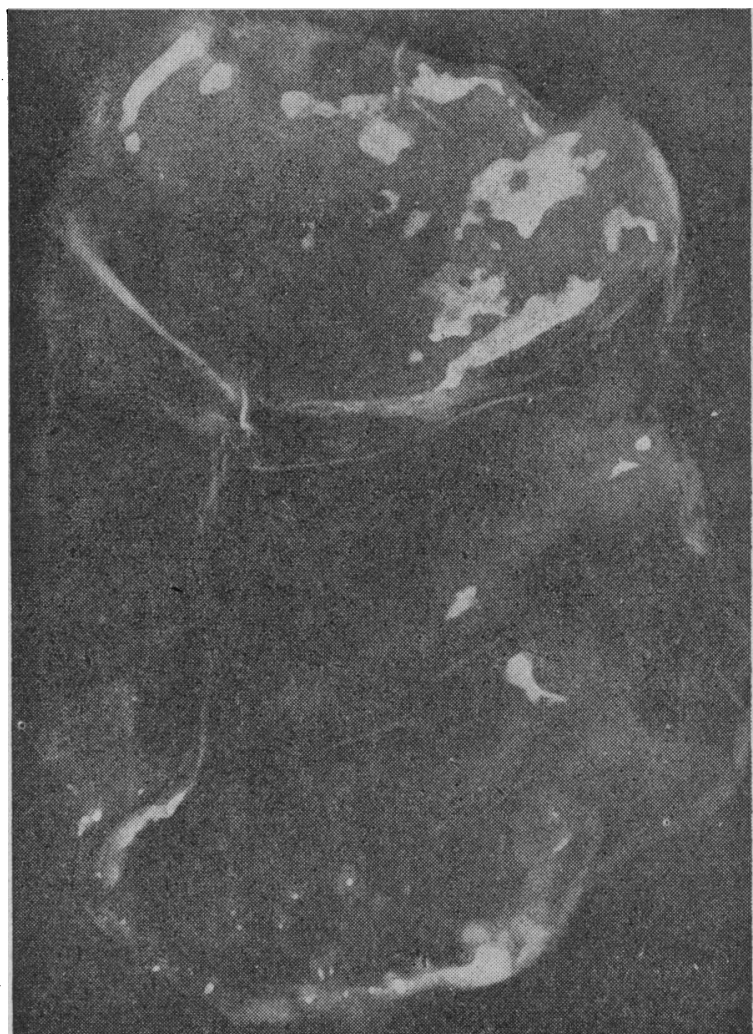

FIG. 2.-X-ray film of parietal pleura shown in Fig. 1. Irregular calcification in largest plaque, with very little in
others. Note the central "spot" of calcification within the nodules in lower part of photograph. 
The majority of plaques $(75 \%)$ were found in men, and most of the subjects died between 50 and 60 years of age. Apart from one woman of 35 who died with a mesothelioma and asbestosis, the youngest patient with a pleural plaque was aged 45 at death. The age and sex incidence correspond to those seen in the radiological series.

\section{Pleural Calcification}

When calcium is present in sufficient amounts, radio-opaque lesions can be detected on chest radiography. During routine reporting of chest radiographs at the London Hospital in the nine-month period beginning June 196436 cases of pleural calcification were seen in patients who had no history of pulmonary tuberculosis or other radiological evidence that might suggest this diagnosis. During this period approximately 27,500 chest radiographs were reported, but a systematic search for these calcific lesions was not carried out. Calcification was usually unassociated with evidence of a parenchymal lung lesion, but in seven cases there was radiological evidence of asbestosis (Hurwitz, 1961), and two others had a pleural effusion, which later was found to be associated

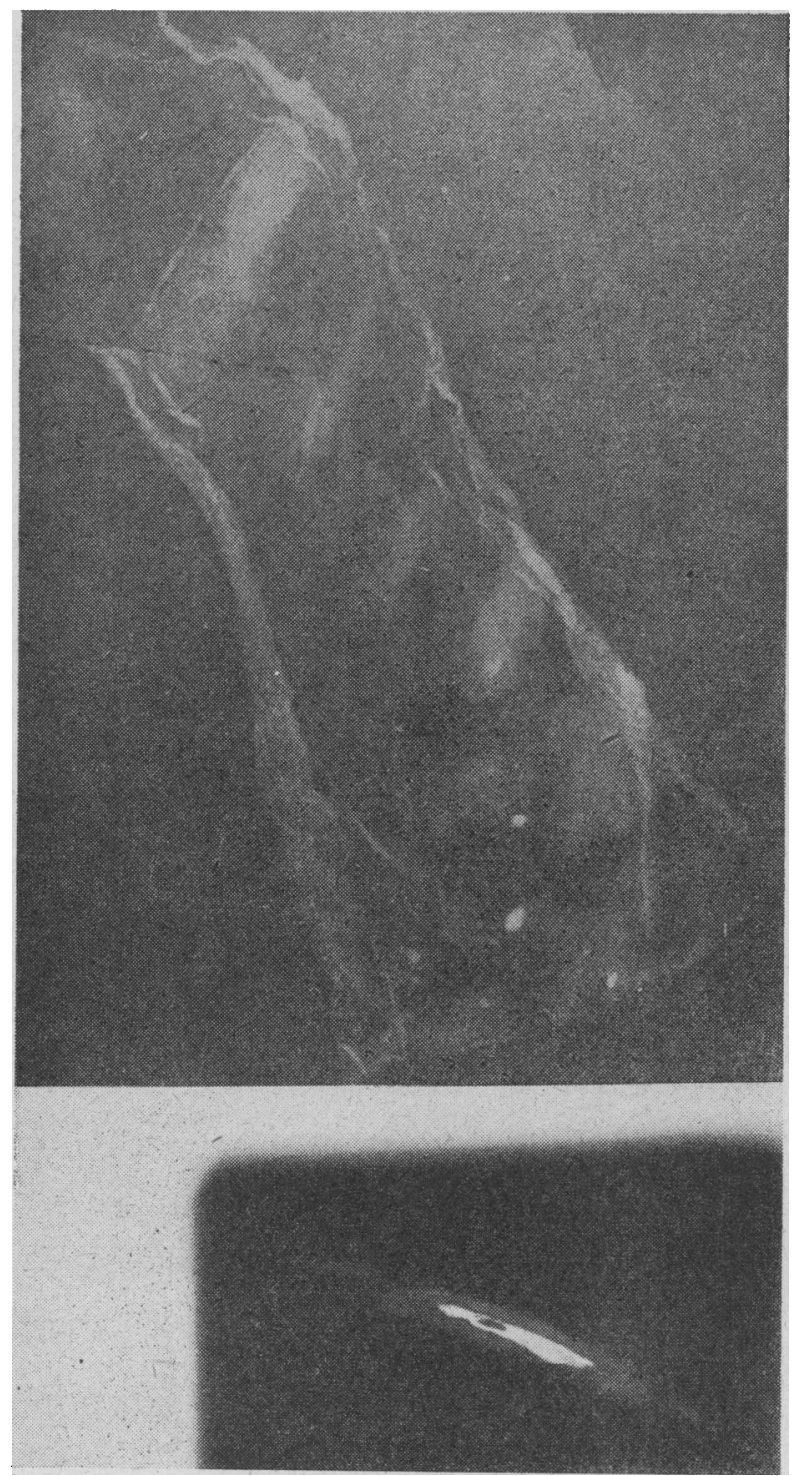

FIG. 3. $-X$-ray film of parietal pleura showing numerous plaques but very little calcification. Lower inset shows a dense zone calcification within a diaphragmatic plaque in the same paienta boiler-lagger for 30 years; he died with peritoneal mesothelioma. with mesothelioma. Usually, but not always, the calcification was bilateral and was found to affect all zones of the lung field, though commonly sparing the apices. Plaques were often noted on the diaphragm, presumably because of its tangential position in regard to the $x$-ray beam. The calcification often had an

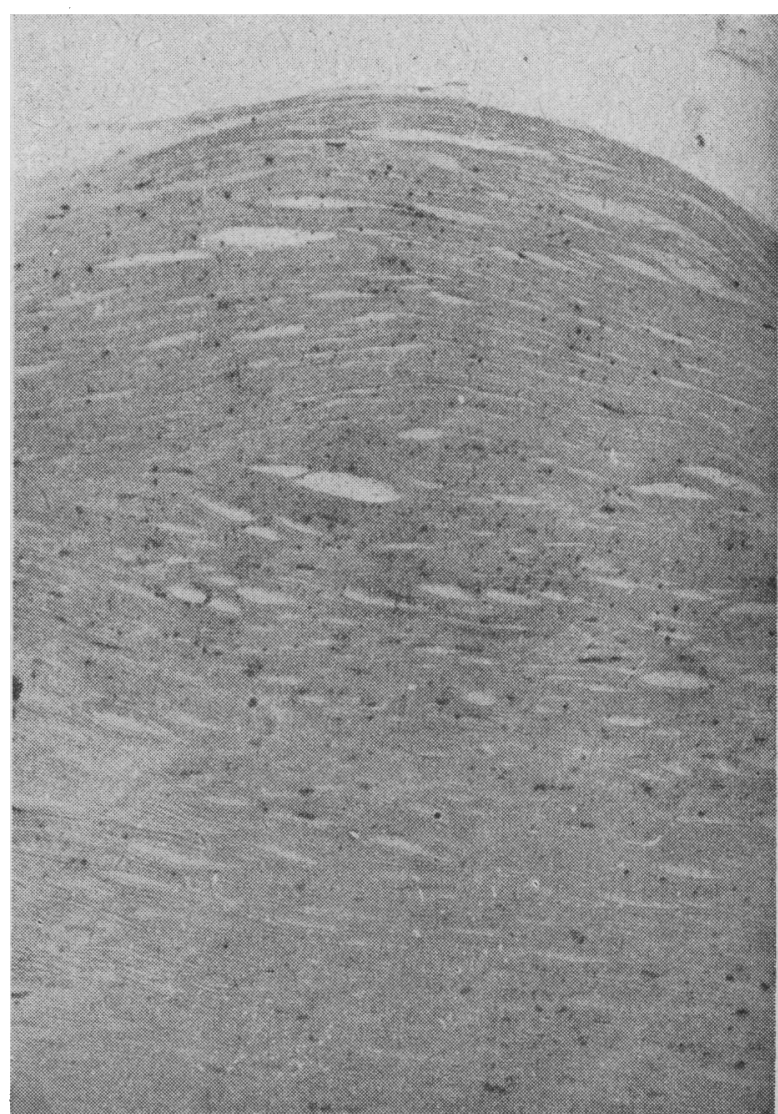

Fig. 4.-Laminated hyaline collagen; the black spots and streaks are calcium salts. (Haematoxylin and eosin. $\times 90$.)

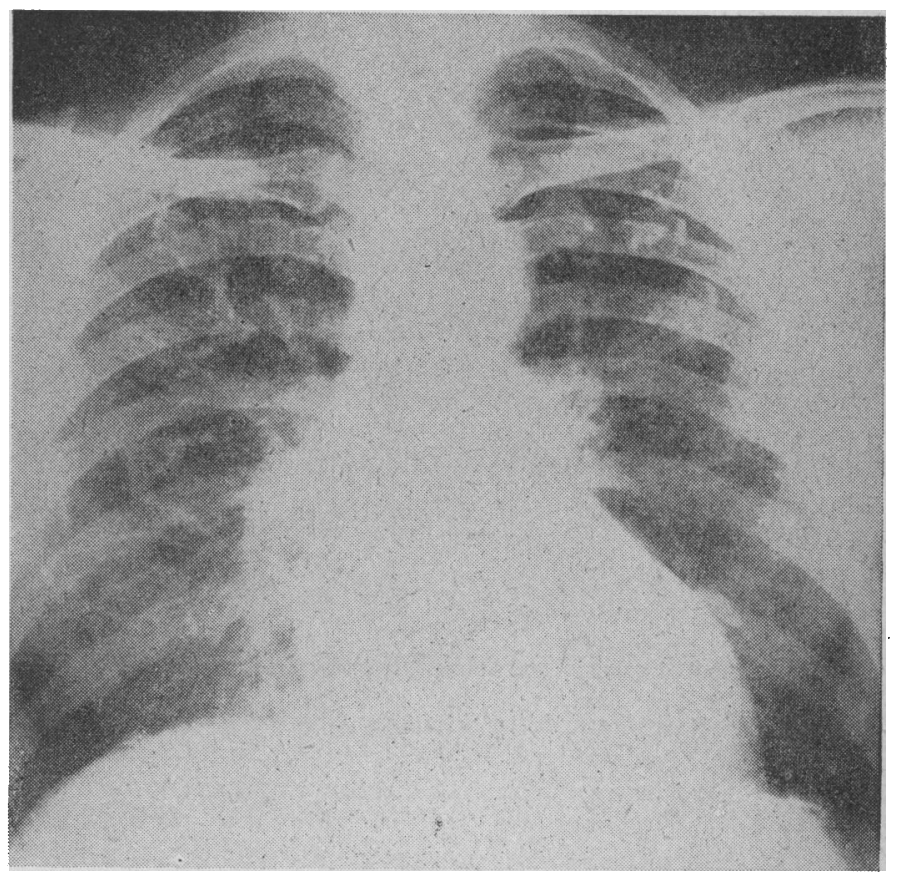

FIG. 5.- $X$-ray film showing speckled " holly-leaf" calcification overlying both lung fields; there are also pla, ues of calcium on bo.h diaphragms. Exposure: patient's garden backed on to an asbesios factory and he lived there until aged 20. Moved from this address 27 years ago. Previous M.M.R. in 1954 was apparently normal. 
uneven or speckled appearance, with irregular outlines like those of a holly leaf (Fig. 5). In one case the calcification was thought to be intrapulmonary, but the occurrence of a partial pneumothorax during aspiration clearly showed the calcification to be pleural (Fig. 6).

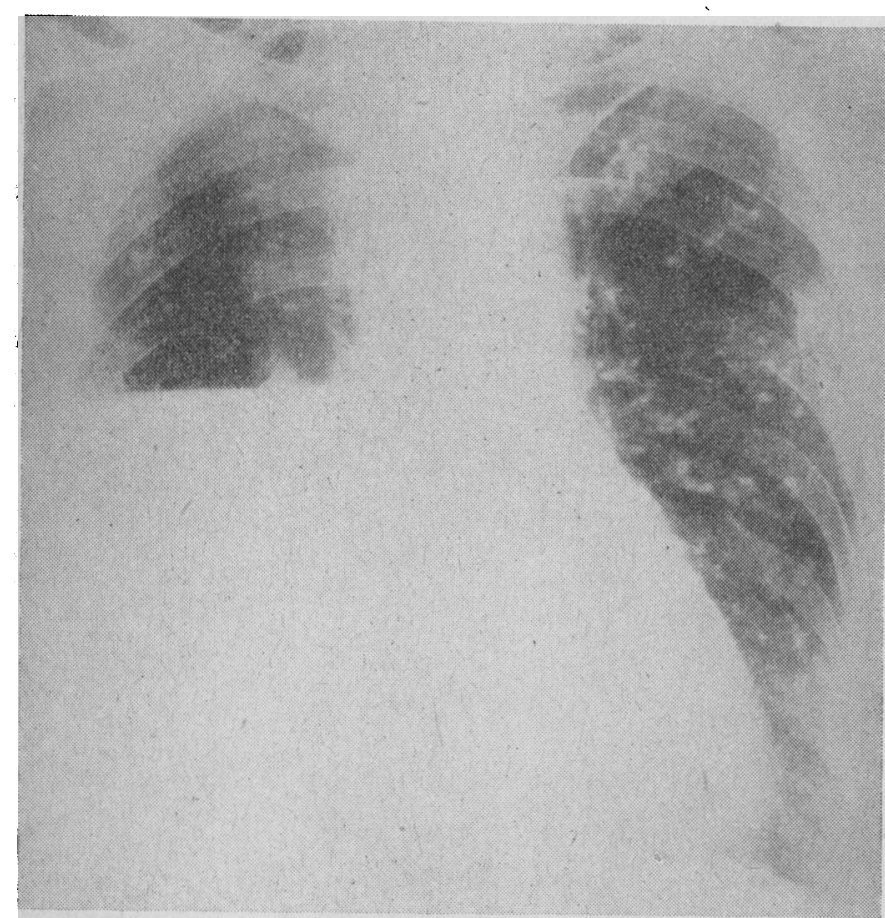

Fig. 6. $-X$-ray film showing calcification overlying left lung field. The right hydropneumothorax following aspiration shows the calcification to be in the parietal pleura. The patient had a mesothelioma of the right pleura, confirmed at necropsy. Exposure was two months in an asbestos factory over 40 years previously.

These findings are at striking variance with the experience of one of us at $x$-ray departments of two other London hospitals. The pleural calcification found in the seven cases with classical radiological evidence of asbestosis was indistinguishable from the calcification present in other cases in the series, including the cases of pleural mesotheliomata. This led to a wider survey, in which the radiographs of 36 cases of clinical asbestosis were examined and pleural calcification was found in eight. A previously published series of 65 cases of mesothelioma (Hourihane, 1964, 1965b) was also examined and six further cases of pleural calcifications were found, making a total of 50 patients in the radiological series. The association of calcified pleural plaques with other radiological abnormalities was not a constant finding. In' 29 out of 36 cases discovered at routine sessions pleural calcification was the only abnormality which might suggest exposure to asbestos. In one case serial chest radiographs were available over a period of nine years. Ínitial radiographs showed one or two small opacities in the right upper zone. Nine years later there were extensive plaques of calcification in both upper lung fields.

\section{Association of Pleural Calcification with Asbestos}

An important failure to identify the lesions in the antemortem chest radiographs became apparent during this study, Only the most dense pleural calcification appeared to be detectable in routine chest $x$-ray films. Radiographs were available from 51 of the 56 subjects in whom plaques had been found at necropsy, and only seven of these had evidence of pleural calcification in life; associated in one with radiological appearances of asbestosis. All seven had histological evidence of asbestosis at necropsy.
In the total radiological series of 50 cases (33 males and 17 females) the ages ranged from 41 to 81 years, with a maximum incidence in the sixth decade. A history of exposure to asbestos was obtained in $43(86 \%)$. Of the 16 tested eight had asbestos bodies in the sputum.

The evidence that pleural calcification, detected radiologically in 36 cases in the absence of a mesothelioma or known asbestosis, was associated with exposure to asbestos is summarized in Table I. A control group of 36 patients, with normal chest $x$-ray films and no history of pulmonary tuberculosis, was

TABLE I.-Types of Asbestos Exposure in 36 Cases of Pleural Calcification. , (Previously Diagnosed Asbestosis or Mesothelioma Excluded from this Group)

\begin{tabular}{|c|c|c|}
\hline Form of Exposure & $\begin{array}{l}\text { Pleural } \\
\text { Plaque } \\
\text { Series }\end{array}$ & $\begin{array}{c}\text { Control Group: } \\
\text { with No Pleural } \\
\text { Plaques }\end{array}$ \\
\hline 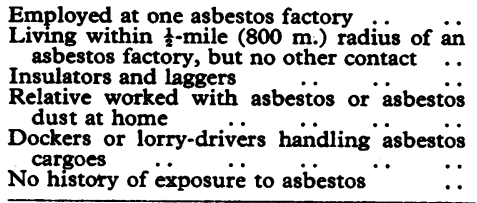 & $\begin{array}{l}11 \\
6 \\
6 \\
2 \\
5 \\
6 *\end{array}$ & $\begin{array}{r}1+ \\
1 \\
0 \\
2 \\
0 \\
32\end{array}$ \\
\hline & 36 & 36 \\
\hline
\end{tabular}

The difference in asbestos exposure between these two groups is statistically significant $(P<0.01)$.

* patient had asbestos bodies in sputum and in lungs.

Employed at asbestos factory for $1 \frac{1}{2}$ days: left "because of dust."

investigated similarly. The patients were matched for age and sex, care being taken to match for in-patient and outpatient status, and all had attended the same $x$-ray department within two months of the group with pleural plaques. A detailed history was taken from each group covering industrial, domestic, and environmental exposure to asbestos, and 4 out of the 36 control subjects gave a history of such exposure. The difference between the test series ( $83 \%$ positive history) and the control $(11 \%)$ is statistically significant $(P<0.01)$.

The exposure to asbestos in the 36 cases in Table I varied considerably. One woman, who had calcified plaques on $x$-ray examination and who died of a malignant melanoma, had been exposed 25 years previously when she had held asbestos sheets intermitteritly over a period of six weeks while her hsuband sawed them to make rabbit hutches. Other patients, especially those employed as boiler-laggers, had been exposed for periods of up to 40 years.

Data concerning the exposure to asbestos in the entire radiological series of 50 cases and the causes of death among the 29 cases with no radiological evidence of asbestosis or mesothelioma are given in Tables II and III.

TABLE II.-Asbestos Exposure in Radiological Series of 50 Cases Average time since first exposure to asbestos (known in 37 cases) $\quad . .0$ Mean duration of exposure in 10 boiler-laggers

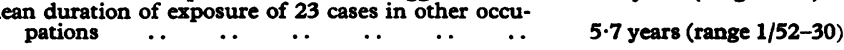

The following is an example of a case history.

A 67-year-old man had a laparotomy for generalized abdominal pain. At operation carcinomatosis peritonei was diagnosed, and this was supported on histological examination. In view of the finding of calcification on the diaphragms, in an otherwise normal chest $x$-ray picture, the histological slide was re-examined and a

TABLE III.-Pleural Plaques as Sole Radiological Abnormality in 29 Cases. Analysis of Causes of Death

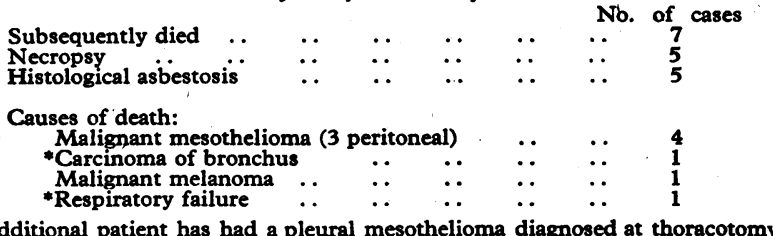

One additional patient has had a pleural mesothelioma diagnosed at thoracotomy and confirmed histologically, and is still alive.

* Necropsy not performed. 
diagnosis of peritoneal mesothelioma was confirmed; there were extensive hyaline pleural plaques (Fig. 3) with little calcification, but denser calcification was present in the diaphragmatic lesions (Fig. 3, inset). Histologically asbestosis was demonstrated at subsequent necropsy, and the patient's widow is claiming compensation, as the patient had been occupied for over 30 years a a boiler-lagger.

\section{Discussion}

It would appear that the population served by the London Hospital has been widely exposed to asbestos, but whether surveys in other districts might show a similar degree of exposure is unknown. It is already known from histological examination of lungs or of lung fluid that evidence of similar asbestos exposure occurs in Capetown (Thomson et al., 1963), in Belfast (Elmes et al., 1965), and in Miami (Thomson, 1966). The striking correspondence between all of these and our own study (asbestos bodies identified in $20-30 \%$ of necropsy subjects) suggests a common widespread environmental contamination of entire urban populations, rather than pollution of restricted areas from single industrial sources. Although many of these areas contain asbestos-using industries, the climatic and social variations between them and the absence of industrial sources for asbestos in Miami suggest that contamination from such sources is unlikely to account for the similar results.

It seems that the radiologically invisible plaques found at necropsy probably reflect this type of community exposure, as only $5 \%$ ( 1 out of 21 ) of these subjects had lived within half a mile ( 800 metres) of a large asbestos factory which is within 7 miles $(11 \mathrm{~km}$.) of this hospital, whereas $30 \%$ (10 out of 30 ) of the radiologically positive series lived within the same radius. The control series was similarly assessed, and $3 \%$ lived within a half-mile radius of the same factory.

It seems to us that the association between asbestos and pleural plaques is so close as to be of value in epidemiological studies, so that the presence of plaques can be taken as evidence of asbestos exposure. There is probably a cause-and-effect relationship between the two, but how asbestos fibres gain access to the serosa is unknown; intracellular carriage within lymphatics seems reasonable to us, though other workersfor example, Kiviluoto (1960)-favour direct penetration of the pleura.

Although $85 \%$ of plaques seen at necropsy have been invisible on postero-anterior chest radiographs, the $15 \%$ which were visible tended to be large extensive lesions (see Fig. 1) with abundant calcification, and were associated with histological pulmonary fibrosis (asbestosis) in each of the seven cases examined. In contrast, most of the necropsy plaques were not associated with asbestosis, as 29 out of 31 did not have' histological asbestosis in the cases detected during routine necropsies at the London Hopital.

From these considerations it would appear that there is a dose-response relationship with regard to the development of these plaques and their detection. Thus, on the one hand, subjects with pleural plaques which were radiologically invisible in life have small plaques with little calcification, rarely have histological asbestosis, have scanty asbestos bodies in the lungs, and have not lived close to a major known source of asbestos. On the other hand, patients with radiologically detectable plaques have large pleural lesions with plentiful calcium, have histological asbestosis with readily detectable asbestos bodies, many live close to an industrial source of asbestos, and most give a history of exposure to asbestos (Table I).

We have found it difficult to unravel the effects of living close to the factory from those of casual labour in it or those of exposure to the clothes of relatives working with asbestos, as all three types of exposure tend to occur together. However, six patients in Table I appeared to have been exposed only through residence close to an asbestos factory, and if these people contract any of the associated neoplastic developments they may be thought to be peculiarly unfortunate, as they have been exposed without their knowledge or consent.

While widespread community exposure to asbestos may be of interest with regard to air pollution, its most immediate significance lies in the disorders to which it may give rise. The effects of a known fibrogenic agent, such as asbestos, upon pre-existing chronic lung disease can hardly be beneficial, but the importance of this is unknown.

It has already been recorded that patients with classical asbestosis have an increased incidence of lung cancer (Doll, 1955), and it is known that pleural or peritoneal mesothelioma may develop in association with asbestos exposure, whether pulmonary fibrosis is present or not (Wagner et al., 1960; Hourihane, 1964). There is no evidence that minimal exposure to asbestos leads to an increase in lung-cancer incidence, and Elmes et al. (1965) found no increase in incidence of asbestos bodies in the lungs of 50 patients with lung cancer compared with matched controls. However, Selikoff et al. (1964), in an epidemiological survey of causes of death of boiler-laggers, found an incidence of lung cancer (42 of 255 deaths out of 632 subjects) which was 6.8 times greater than expected, and the incidence of asbestosis in this group was low (12 deaths out of 255). Consequently, we feel that the possibility of a relationship between mild or transient exposure to asbestos and the subsequent development of lung cancer remains, and further work in this area is required before a conclusion can be reached. We feel that radiological surveys of populations to ascertain the prevalence of pleural plaques might be of value in this regard.

We have no evidence to offer concerning lung cancer in the small groups of patients in our study, as with such a common neoplasm large numbers are required for interpretation of significance. However, follow-up of our 22 living patients with radiological plaques will be of interest.

Diffuse mesotheliomata of pleura or peritoneum are uncommon, and the fact that five of the nine deaths out of 36 patients in the radiological series were due to these neoplasms is striking. In addition, one patient with a pleural mesothelioma is still alive. Of the total of 56 subjects in the necropsy series $15(27 \%)$ had mesotheliomata (10 peritoneal, 5 pleural). If the patients with classical asbestosis are excluded the incidence was $9(23 \%)$ out of 40 necropsies ( 5 peritoneal, 4 pleural), and if the subjects with histological asbestosis are also excluded the incidence falls to $3(9 \%)$ out of 32 ( 0 peritoneal, 3 pleural). This is an extremely high rate for this tumour, and shows a trend of rising incidence with greater exposure to asbestos. As one-quarter of our necropsy population show asbestos bodies in the lungs, and as the incidence of diffuse mesotheliomata at necropsy during the years $1950-63$ has been approximately $0.3 \%$, it is probable that the pleural reaction which leads to plaque formation reflects an additional hazard of serosal malignancy.

Thus the incidence of mesothelioma appears to vary with degrees of asbestos exposure and quantity of asbestos found at necropsy from $0.3 \%$ of all necropsies to $27 \%$ of the 56 cases with plaques at necropsy. This figure approaches that found in a series of cases of classical asbestosis, in which the asbestos is usually present in greatest amount (Hourihane, 1965a).

Pleural plaques and diffuse mesotheliomata have a number of features in common. Both affect parietal pleura preferentially, both are associated with exposure to asbestos and contain asbestos fibres, and they have certain macroscopic similarities. It is tempting to regard the plaques as benign forerunners of mesotheliomata; but we prefer to regard them as independent markers of a reaction to asbestos, as we have never seen transitions between the two despite their coexistence in several instances, and peritoneal rather than pleural neoplasms seem especially frequent when plaques are present.

We are reluctant to accept the suggestion of Selikoff et al. (1964), than cancer of the stomach and rectum may occur with increased frequency in asbestos-workers, until these cases have 
been shown not to be peritoneal mesotheliomata, since the clinical course and macroscopic appearances of these neoplasms can be very similar (Hourihane, 1964).

While necropsy and radiological surveys of other populations would be of great interest, and while the hazards of asbestos exposure are in need of more detailed analyses, the preventive and legal aspects of industrial, domestic, and environmental exposure require urgent consideration. Once pleural plaques have developed the dangers of supervening malignancy are great and the possibility of successful treatment is remote.

\section{Summary}

A close association between exposure to asbestos and the development of pleural plaques has been shown. A cause-andeffect relationship is probable. The most extensive lesions are radiologically detectable, and the disease asbestosis is then also present, despite the absence of any other radiological abnormality.

The sources of asbestos are considered and evidence is presented to suggest that there is a widespread non-industrial community exposure. Mesotheliomata are common in patients with pleural plaques, and it is suggested that there is a doseresponse relationship between the asbestos and the development of these neoplasms.

The question of a relationship between lung cancer and asbestos is left open, but the value of radiological surveys for pleural plaques is emphasized in any study of this problem.
Asbestos is not the sole cause of pleural plaques, but it is certainly the most common.

We should like to thank the physicians and surgeons of the London Hospital who allowed us to refer to cases under their care, and the registrars of the $x$-ray department who helped us to collect the radiological series. We are grateful to Professor I. Doniach, Dr. N. Lloyd-Rusby; and Dr. L. J. Rae for encouragement and assistance. We are indebted to Mr. Moss and the film store for their help in tracing a large number of films, to Miss R. L. Cresswell for secretarial assistance, and to the photographic department for the illustrations.

\section{REFERENCES}

Doll, R. (1955). Brit. 7. industr. Med., 12, 81.

Elmes, P. C., McCaughey, W. T. E., and Wade, O. L. (1965). Brit. med. 7., 1,350 .

Gloyne, S. R. (1933). Tubercle (Lond.), 14, 445, 493, 550

(1938). In Silicosis and Asbestosis, edited by A. J. Lanza. Oxford Univ. Press, London.

Heard, B. E., and Williams, R. (1961). Thorax, 16, 264.

Hourihane, D. O'B. (1964). Ibid., 19, 268.

- (1965a). M.D. Thesis, National University of Ireland. (1965b). Ann. N.Y. Acad. Sci., 132, 647.

Hurwitz, M. (1961). Amer. 尹. Roentgenol., 85, 256.

Kiviluoto, R. (1950). Acta radiol. (Stockh.), Suppl. No. 194.

Lawson, J. P. (1963). Clin. Radiol., 14, 414.

Selikoff, I. J., Churg, J., and Hammond, E. C. (1964). F. Amer. med. Ass., 188, 22.

Ass., 188, 22. (1952). Amer. F. Roentgenol., 67, 375.

Thomson, J. G. (1966). Ann. N.Y. Acad. Sci. In press.

Kaschula, R. O., and MacDonald, R. R. (1963). S. Afr. med. F., 37, 77.

Wagner, J. C., Sleggs, C. A., and Marchand, P. (1960). Brit. F. industr. Med., 17, 260.

\title{
Effect of Aggregating Agents on the Electrophoretic Mobility of Human Platelets
}

\author{
J. R. HAMPTON,* M.A., B.M., M.R.C.P.; J. R. A. MITCHELL, † M.D., D.PHIL., M.R.C.P.
}

Brit. med. F., 1966, 1, 1074-1077

In the presence of very low concentrations of adenosine diphosphate (A.D.P.), adenosine triphosphate (A.T.P.), 5-hydroxytryptamine (5-HT), and the adrenalines (Gaarder et al., 1961 ; Mitchell and Sharp, 1964) platelets in a citrated plasma system adhere together to form aggregates, but the mechanism of this type of aggregation is unknown. Platelets carry a negative surface charge (Abramson, 1928), and they would normally be expected to repel each other; during aggregation the electrostatic forces must be overcome. The surface charge on cells can be measured by determining their electrophoretic mobility, and we considered that a study of the effect of the various aggregating agents on platelet charge might yield information on the nature of the clumping process. This paper reports the results of these studies.

\section{Methods}

Blood samples were obtained from healthy volunteers and from medical and surgical patients who did not have acute inflammatory conditions. Platelets from subjects with a variety of inflammatory states (pneumonia, phlebitis, pericarditis, and temporal arteritis) and with recent myocardial infarctions or pulmonary emboli behave abnormally and will be described separately (Hampton and Mitchell, 1966b).

Platelet-rich and platelet-poor citrated plasma were prepared, and the platelets were brought into contact with glass, as described previously (Hampton and Mitchell, 1966a). Platelet-rich citrated plasma was diluted 1 in 10 with plateletpoor citrated plasma or with the other media specified below, and the electrophoretic mobility of platelets was measured in the horizontal capillary apparatus developed by Bangham et al. (1958). All measurements were made at $25^{\circ} \mathrm{C}$. with a potential gradient of $2.66 \mathrm{~V} / \mathrm{cm}$. The mobilities are expressed as $\mu / \mathrm{sec} . / \mathrm{V} / \mathrm{cm}$.

\section{Effect of A.D.P. and Noradrenaline on Mobility}

The post-contact mobility of platelets in a platelet-rich! platelet-poor citrated plasma mixture was measured. A.D.P. or noradrenaline (both from Sigma) was dissolved in $0.85 \%$

\footnotetext{
* Junior Lecturer, Department of the Regius Professor of Medicine, the Radcliffe Infirmary, Oxford.

+ First Assistant, Department of the Regius Professor of Medicine, the Radcliffe Infirmary, Oxford.
} 